\title{
A grande estratégia dos Estados Unidos para o Tribunal Penal Internacional no pós-Guerra Fria
}

Marrielle Maia Alves Ferreira'

\section{Resumo}

O presente artigo tem a finalidade de estudar a grande estratégia desenhada pelas administrações George H. W. Bush (1989-1992), Bill Clinton (1993-2000) e George W. Bush (2001-2008) e Barack Obama (2009-2012) com vistas a discutir as variações da política externa dos Estados Unidos para instrumentos de justiça internacional penal, com foco para o Tribunal Penal Internacional. A análise toma como embasamento o conceito ampliado de grande estratégia, com foco na interação entre dois elementos do núcleo duro do interesse nacional dos Estados Unidos, a segurança e os american values. A partir disto, é explicitado o consenso subjacente às posições das diferentes administrações sobre os tribunais penais internacionais e, mais genericamente, os regimes internacionais de Direitos Humanos. Também serão discutidas as dimensões específicas do dissenso sobre esses temas.

Palavras-chave: grande estratégia, Estados Unidos: política externa, direito internacional penal.

\section{Introdução}

O fim da Guerra Fria inaugurou uma época de redefinição da política externa e estratégia de inserção internacional dos Estados Unidos, bem como do descongelamento de alguns temas da agenda internacional, entre eles, o da criação de um instrumento de justiça penal internacional permanente.

Até então a estratégia da contenção da União Soviética e do comunismo acomodara os debates sobre os princípios e objetivos da política externa dos Estados Unidos. Essa acomodação em torno da grande estratégia da contenção

Doutora em Ciência Politica pela Universidade Estadual de Campinas - Unicamp (20 II), professora adjunta DEll da Universidade Federal de Uberlândia (UFU). Uberlândia, Minas Gerais, Brasil, e coordenadora do Grupo de Estudos sobre os Estados Unidos do Instituto de Economia da UFU. É autora de artigos publicados nas revistas: Meridiano 47 (Universidade de Brasília - UnB), 2013; Revista Internacional de Direito e Cidadania, 2012; Primeiros Passos, 2008 e Cena Internacional (UnB), 200I.E-mail: marrielle@ie.ufu.br. 
nâo significou, entretanto, a ausência de debates e desenhos de táticas diferentes dos governos no período (PECEQUILO, 2005). De toda a forma, a época foi marcada pelo engajamento dos Estados Unidos na construçáo da nova ordem internacional, caracterizada pela relaçáo entre a agenda de segurança e a preservaçáo da expansão dos valores norte-americanos ${ }^{2}$. Foram várias as instituiçóes criadas com o apoio dos Estados Unidos com vistas a moldar a ordem internacional do pós-Segunda Guerra Mundial: a Organizaçáo das Naçóes Unidas, o Sistema de Bretton Woods, a Organizaçáo do Tratado Atlântico Norte. No entanto, a negociaçáo para a criaçáo de uma instituiçáo internacional julgar crimes internacionais foi protelada.

A proposta de criaçáo de uma corte penal internacional permanente encomendada pela Assembleia Geral da ONU para a Comissáo de Direito Internacional em 1948 - fortemente influenciada, de um lado, pelo apelo internacional em favor do fim da impunidade para crimes internacionais e, de outro lado, pelas críticas à justiça de exceção promovida pelos Tribunais Militares de Nuremberg e de Tóquio - não obteve êxito, segundo Scharff (1997), em razáo da lógica da Guerra Fria³

$\mathrm{Na}$ esteira das transformaçóes da política internacional depois da queda do muro de Berlim, debates políticos e acadêmicos sobre a nova grande estratégia dos Estados Unidos ganharam destaque ${ }^{4}$. Foi nesse contexto de debates e

2 Pecequilo (2005), ao analisar as políticas adotadas pelos nove presidentes identificados com a Guerra Fria, divide em cinco fases as variações de prioridades e táticas no periodo: a confrontação (de 1947 a 1962), a coexistência (de 1963 a 1969), a détente (de 1969 a 1979), a confrontação renovada (de 1979 a 1985) e a retomada do (de 1986 a 1989).

3 O autor aponta, por exemplo, que o julgamento de crimes como o de agressão, no contexto da Guerra Fria, era visto pelos tomadores de decisão nos Estados Unidos como uma ameaça à soberania nacional. Além disso, grandes potências não estavam dispostas a ceder para um órgão judicial internacional a competência pela investigação da legitimidade do uso da força.

4 Algumas obras lançadas a partir do fim da década de 1980 capturam essa realidade como, por exemplo, a obra "O Fim da História" de Francis Fukuyama (1989), cujo argumento defende que a derrocada do socialismo tem como resultado a reafirmação democracia liberal ocidental como única forma de governo humano. $O$ argumento de Fukuyama indicava a promessa de uma era de harmonia global, cuja rivalidade dos Estados daria lugar à cooperação promovida pela hegemonia benigna dos Estados Unidos através do incentivo ao capitalismo, desenvolvimento e expansão das democracias. As reações à profecia do fim da história e a defesa da unipolaridade não demoraram a aparecer. La Faber e Bruce Cumings em publicação sobre o significado $e$ as implicações do fim da Guerra Fria argumentam que o evento não constitui uma fissura com o passado. nem o fim da competição internacional, muito menos das diferenças e dos conflitos ideológicos entre a Rússia e os Estados Unidos e o mundo desenvolvido e em desenvolvimento. Huntington (1993) na conhecida obra "The Clash of Civilizations?" reafirma que o fim da Guerra Fria não significa o fim dos conflitos internacionais 
políticas com vistas a moldar a nova grande estratégia dos Estados Unidos, que o tema da criaçáo de um tribunal penal internacional permanente retornou para a agenda da Organizaçáo das Naçóes Unidas. No ano de 1989, Trinidad e Tobago apresentaram a proposta da criaçáo de um tribunal que pudesse julgar crimes transnacionais, como o do tráfico de drogas e da lavagem de dinheiro, além dos crimes já consagrados no direito internacional (crime de guerra, crime contra a humanidade, crime de genocídio e o crime contra a paz ou de agressão). Três anos depois, tribunais criminais de exceção foram criados pelo Conselho de Segurança para julgar atrocidades cometidas durante os conflitos na ex-Iugoslávia (1993) e em Ruanda (1994), bem como tribunais mistos5.

As negociaçóes para a criação do Tribunal Penal Internacional iniciaram em 1996 e tiveram sua conclusão com o Tratado de Roma aprovado em 1998, que estabeleceu um mecanismo permanente com jurisdiçáo complementar sobre os crimes de genocídio, crimes contra a humanidade, crimes de guerra e crimes de agressão. De acordo com o seu Estatuto, o Tribunal pode ser acionado por meio de queixa de um Estado para a promotoria, pela promotoria, proprio motu, ou pelo Conselho de Segurança em situaçóes particulares relacionadas ao Capítulo VII da Carta das Naçóes Unidas (MAIA, 2012).

A postura ambígua dos Estados Unidos sobre o Tribunal Penal Internacional, durante e após as negociaçóes, permite identificá-los como um dos principais promotores da justiça internacional de exceçáo e um dos principais opositores da justiça internacional permanente representada pelo Tribunal Penal Internacional.

Alguns estudiosos explicam que a posiçáo política norte-americana com relaçáo aos tribunais criminais internacionais é parte da política paradoxal dirigida aos tratados de direitos humanos, ou seja, o Estado promove a criaçáo desses mecanismos internacionais, mas não adere a estes, o que é justificado,

que passam a ter caracteristica diversa do periodo anterior, um conflito civilizacional. Alguns estudos como o de Posen e Ross (1997) categorizaram as opções estratégicas para os Estados Unidos nos anos futuros que, em linhas gerais, retomavam as tradições isolacionista (com a defesa do desengajamento dos compromissos internacionais assumidos durante a Guerra Fria) e internacionalista (com o argumento da necessidade do engajamento internacional na construção e manutenção da ordem mundial) da política externa dos Estados Unidos.

5 Os tribunais mistos são criados pela Organização das Nações Unidas e possuem um corpo de juizes formado por magistrados nacionais e estrangeiros. Exemplos desses tribunais são os do Timor Leste (2000), Serra Leoa (2002), Camboja (2003) e Libano (2007). 
de um lado, pela dificuldade de aprovação de tratados internacionais pelo legislativo do país e, de outro, pelo fato de a abordagem da política externa norte-americana para os direitos humanos ser bilateral (APODACA, 2006; SIKKINK, 2004; MERTUS, 2004; FORSYTHE, 2000; STEINMETZ, 1994).

No entanto, o caso do Tribunal Penal Internacional é diferente, os Estados Unidos além de nâo ratificarem seu tratado constitutivo, iniciaram no governo George W. Bush uma política ativa de oposiçáo e boicote ao Tribunal com medidas como: (a) aprovaçáo de resoluçóes no Conselho de Segurança restringindo a atuação do Tribunal Penal Internacional; (b) estabelecimento de acordos bilaterais de náo entrega de oficiais norte-americanos ao Tribunal Penal Internacional; e (3) aprovação de legislaçáo doméstica que autorizou o Presidente dos Estados Unidos a usar força militar para obstruir as operaçóes do Tribunal Penal Internacional e a retirada de ajuda financeira e militar para países membros do Tribunal (SHABBAS, 2004, p. 1-2).

Uma explicação para a oposiçáo ao Tribunal Penal Internacional no governo W. Bush foi dada por Bolton (2003), que ressaltou o fato da competência do Tribunal de julgar nacionais de Estados nâo membros de seu estatuto constitutivo ir de encontro aos interesses do referido governo de patrocinar a "guerra contra o terror" por meio de intervençóes armadas, muitas vezes unilaterais.

Não obstante essa interpretaçáo, conforme adverte Ralph (2003), a oposição norte-americana ao Tribunal Penal Internacional não deve ser entendida como circunscrita à administraçáo George W. Bush ou aos núcleos de defensores de uma política unilateral e intervencionista, que tem como objetivo maximizar a margem de manobra norte-americana ao náo assumirem o que consideram como compromissos internacionais desnecessários (MAIA, 2012, p. 20). A oposiçáo ao Tribunal Penal Internacional deve ser analisada de forma a considerar a estratégia mais ampla de engajamento internacional dos Estados Unidos.

Nesse contexto, o presente artigo tem como objetivo estudar as variaçóes da política externa dos Estados Unidos para instrumentos de justiça internacional penal, com foco para o Tribunal Penal Internacional. O estudo foi realizado por meio de uma análise dos posicionamentos oficiais das quatro administrações norte-americanas que se seguiram no pós-Guerra Fria $(\mathrm{H}$. Bush, Bill Clinton, W. Bush e Barack Obama) expressos nos relatórios de estratégia 
de segurança nacional que, por força de lei, devem ser publicados anualmente pelo poder executivo estadunidense. Como algumas administraçôes não cumpriram a legislaçáo sobre o tema, foram realizados o levantamento e a análise de todos os relatórios publicados por cada administração, no total de treze documentos.

Vale destacar que esses documentos expressam a posição oficial dos governos sobre a grande estratégia dos Estados Unidos e refletem náo apenas as políticas de defesa propostas por cada administraçáo norte-americana, mas as de engajamento internacional com vistas ao alcance dos interesses nacionais que são definidos como: segurança, valores americanos (entre eles democracia e direitos humanos) e prosperidade econômica (MAIA, 2012, p. 124). Assim, este trabalho parte da premissa de que é possível atribuir um sentido geral da política dos Estados Unidos para os mecanismos de proteçáo dos Direitos $\mathrm{Hu}$ manos (como o caso dos tribunais criminais internacionais) a partir da análise da grande estratégia, em cuja ótica suas políticas são elaboradas nesse campo.

\section{O Conceito de Grande Estratégia nos Relatórios de Segurança Nacional}

A definição de grande estratégia não é consensual entre os estudiosos do tema. Parte dos autores defende que o termo está relacionado às projeçōes militares para lidarem com as ameaças (MERSHEIMER, 1998; ART, 1991). Outros autores como Layne (1998) adotam um conceito mais amplo que permite abarcar a combinaçáo de meios (os mais diversos) e fins ligados ao interesse nacional para a perseguiçáo da segurança em tempos de guerra e de paz.

Os Estados Unidos têm adotado em seus documentos de estratégia de segurança nacional uma concepção ampliada, mais próxima de Layne (1998). No "DOD Dictionary", grande estratégia é remetida ao termo estratégia de segurança nacional e traz a seguinte definição: "Um documento aprovado pelo Presidente dos Estados Unidos para o desenvolvimento, aplicaçáo e coordenaçáo dos instrumentos do poder nacional para atingir objetivos que contribuem para a segurança nacional" (U.S. DEPARTMENT OF DEFENSE, 2001, p. 371, traduçáo nossa).

O documento sobre o qual o Dicionário do Departamento de Defesa se refere é o Relatório de Segurança Nacional que, por força de lei, estabelece 
a obrigação dos presidentes norte-americanos de apresentarem um relatório anual sobre a articulação da grande estratégia. O órgão da administração responsável por receber sugestỏes, preparar documentos preliminares para negociaçáo e aprovar o documento final é o Conselho de Segurança Nacional, formado por: vice-presidente, Secretário de Estado, Secretário de Defesa, Diretor da Agência Central de Inteligência - CIA e Conselheiro de Segurança Nacional (MAIA, 2012, p. 125).

O processo de formulação da grande estratégia inicia-se com a identificação dos valores nacionais dos quais derivam o núcleo do interesse nacional. $\mathrm{O}$ interesse nacional está sempre relacionado ao tripé segurança, valores e prosperidade econômica. Na formulação do relatório, as lideranças governamentais apresentam a abordagem sobre os meios para atingir o interesse nacional. São também identificados os desafios e as ameaças que podem derivar de atores específicos no sistema internacional ou de movimentos e de tendências observados no sistema (DORFF, 2001, p. 19).

Nesse contexto, a política nacional é derivada do desenho estratégico que passa pelas seguintes etapas: (a) identificação do interesse nacional; (b) identificaçáo da intensidade do interesse; (c) análise do cenário e das oportunidades; (d) identificaçáo dos objetivos; (e) identificação dos meios para atingir os objetivos; (f) estudo das opçóes estratégicas; (g) avaliação dos riscos; (h) recomendaçóes políticas.

É importante observar que os meios identificados para atingir os objetivos relacionados ao interesse nacional náo são apenas militares. Ademais, os relatórios não refletem apenas as políticas de defesa propostas por cada administração, mas as de engajamento internacional para alcançar os interesses nacionais definidos como segurança, valores americanos (entre eles democracia e direitos humanos) e prosperidade econômica.

O processo anteriormente descrito tem servido de guia para a formulação dos relatórios de estratégia de segurança nacional desde a administração Ronald Reagan, a primeira a publicar o documento por força de lei. Após o fim da Guerra Fria, e no período compreendido entre as administraçóes George H. W. Bush e Barack Obama foram apresentados ao Congresso treze relatórios de segurança nacional: George H. W. Bush (1990, 1991 e 1993), Bill Clinton (1994, 1995, 1996, 1997, 1998, 1999, 2000), George W. Bush (2002 e 2006), Barack Obama (2010). 
Os relatórios de segurança nacional das quatro administraçôes foram escolhidos como fontes da presente pesquisa em razáo da abordagem que relaciona os tribunais criminais internacionais (de forma específica) e os regimes de direitos humanos (de forma geral) aos objetivos e meios de alcance do interesse nacional dos Estados Unidos na sua grande estratégia. A pesquisa busca explicitar e analisar os consensos e dissensos observados nas abordagens dos quatro governos estudados.

\subsection{Os instrumentos de justiça penal internacional na grande estratégia de George H. W. Bush}

George H. W. Bush iniciou sua administração em 1989 e publicou em 1990 o seu primeiro relatório de estratégia de segurança nacional. A principal preocupaçáo apresentada pelo presidente foi a de superar as dificuldades da mudança de foco estratégico com o fim da Guerra Fria. O relatório também ressalta a vitória da estratégia de contençáo, mas reconhece o declínio do poder norte-americano e a necessidade de açóes coletivas para a garantia da segurança internacional.

Os interesses nacionais foram assim listados: (1) a sobrevivência dos Estados Unidos como nação livre e independente, com seus valores fundamentais intactos com instituiçóes e pessoas seguras; (2) a saúde e o crescimento $\mathrm{da}$ economia estadunidense para assegurar oportunidade para a prosperidade individual e recursos para garantir o desempenho nacional dentro e fora do território; (3) um mundo seguro e estável com a promoçáo da liberdade, direitos humanos e instituiçóes democráticas; (4) relaçóes politicamente vigorosas, saudáveis e cooperativas com aliados e naçôes amigas (THE WHITE HOUSE, 1990, p. 2-3).

Ademais, com vistas a manter a superioridade norte-americana, foi recuperada a estratégia de contençáo para o enfrentamento de novas ameaças (as armas de destruição em massa, o terrorismo, a criminalidade transnacional e os Estados em condiçóes calamitosas).

O tema dos direitos humanos aparece no documento atrelado aos valores da promoção da democracia, liberdade e livre mercado. É privilegiada uma abordagem bilateral para a promoção dos direitos humanos, ou seja, uma política voltada para os outros e com um viés assistencialista. A abordagem 
multilateral do tema aparece quando relacionada à segurança internacional $\mathrm{e}$ às alianças com as naçôes que compartilham valores americanos. Sobre as instituiçóes internacionais, uma mençáo apenas é feita no tópico do relatório que lista os objetivos para o ano de 1990. O texto declara o interesse em "fazer as instituiçóes internacionais mais efetivas na promoçâo da paz, ordem mundial e progresso político, econômico e social" (THE WHITE HOUSE, 1990, p. 2).

É no relatório de 1991 que o interesse de "perseguir a justiça internacional" é contemplado. A transiçáo da estratégia de contençáo para o engajamento coletivo é feita em um período de otimismo com a açáo coletiva na Guerra do Golfo. O período também foi marcado pelo interesse da criaçáo de um tribunal internacional para julgar Saddam Hussein. A ideia foi promovida pela administração norte-americana, mas como o governo não estava disposto a perseguir a ideia unilateralmente e envolver a Organizaçáo das Naçóes Unidas no processo levou a sugestáo para a Liga Árabe que, embora tenha discutido o tema, náo o levou adiante (BASSIOUNI, 2005). Apesar da relutância no envolvimento em crises humanitárias, como as da Somália e da ex-Iugoslávia, outra iniciativa de criação de instrumentos de justiça penal internacional ocorreu em dezembro de 1992, quando o Secretário de Estado Eagleburger propôs no Conselho de Segurança das Naçóes Unidas que os criminosos de guerra do conflito da ex-Iugoslávia fossem levados a julgamento.

O último relatório da administraçáo George H. W. Bush teve seu preparo iniciado em 1992, mas a campanha eleitoral adiou os trabalhos de conclusáo, e o documento somente foi publicado em janeiro de 1993. Este reforça a estratégia de engajamento coletivo em bases regionais que, em matéria de defesa, continuou a ser desenhado por Dick Cheney e Colin Powell.

A ênfase na "paz democrática" e na necessidade da liderança norte-americana, baseadas nos princípios gêmeos da democratizaçáo e economia de mercado, mais tarde ganhou expressáo também na estratégia de Clinton de engajamento e alargamento.

\subsection{Os instrumentos de justiça internacional na grande estratégia de Bill Clinton}

Bill Clinton assume a presidência dos Estados Unidos em 1993 com prioridades de governo claramente domésticas, o que rendeu críticas da oposição 
sobre a sua inexperiência em assuntos internacionais. Nos seus dois mandatos, Bill Clinton publicou sete relatórios. Nos primeiros três anos (1994, 1995 e 1996) os documentos receberam o título de "A National Security Strategy of Engagement and Enlargement". Nos anos posteriores (1997, 1998, 1999, 2000), os documentos receberam o título de "National Security Strategy for a New Century".

Os primeiros relatórios de estratégia de segurança nacional publicados em 1994, 1995 e 1996 demonstram a preocupação de transmitir as prioridades estratégicas de engajamento internacional do governo. A manutençáo da posição de primazia dos Estados Unidos norteou a grande estratégia, cujas açóes centrais foram assim descritas: (1) aumentar a segurança, mantendo uma capacidade de defesa forte e empregando uma diplomacia eficaz para promover medidas de segurança cooperativa; (2) abrir mercados estrangeiros e estimular o crescimento econômico global; e (3) promover a democracia no exterior (THE WHITE HOUSE, 1994, 1995, 1996).

Os documentos detalharam as chamadas novas ameaças que, diferentemente da interpretaçáo da administraçáo do governo anterior, foram considerados como mais diversificadas e de mais difícil tratamento. A concepção de segurança foi alargada e definida como a proteção do povo, do território e do modo de vida norte-americano. Nesse sentido, o combate aos chamados rogue states e o tema da expansão das democracias ganhou relevância nos relatórios (THE WHITE HOUSE, 1995, p. 2).

O tema dos direitos humanos, assim como no governo anterior, aparece nos documentos como um valor norte-americano que deve ser promovido no exterior em uma agenda bilateral e assistencialista. $\mathrm{Na}$ agenda multilateral, o tema volta a aparecer, mas ligado às questóes estratégicas de expansão das democracias e do livre mercado. Nas palavras de Apodaca (2006), Bill Clinton somente apoiou os direitos humanos quando estes eram compatíveis com outras preferências políticas, especialmente econômicas (APODACA, 2006, p. 162).

Com forte ligaçáo com os temas da expansáo das democracias, intervençóes humanitárias e direitos humanos, o tema dos tribunais ad hoc e mistos, criados pela Organização das Naçóes Unidas, fez também parte dos documentos. Os tribunais foram apontados como um meio de dissuasáo dos violadores do direito internacional, em especial lideranças de estados em situação de conflito étnico e dos rogue states (THE WHITE HOUSE, 1995, p. 23-24). 
O Tribunal Penal Internacional permanente somente foi mencionado no relatório de 1996, quando as reunióes do Comitê Preparatório para a Conferência de Plenipotenciários do tratado que criou o referido Tribunal iniciaram seus trabalhos. O relatório declara o endosso do Presidente à criação de um tribunal penal permanente dirigido às violaçóes do direito internacional humanitário (THE WHITE HOUSE, 1996, p. 32).

Vale lembrar que, no ano de 1993, o tema da criaçáo de um tribunal permanente foi introduzido na agenda da Organizaçáo das Naçóes Unidas, e os Estados Unidos envidaram esforços de adiar o tratamento do tema. Todavia, foram muitos os discursos da administraçáo Bill Clinton favoráveis à criação do referido instrumento jurídico ${ }^{6}$. Depois do relatório de 1996, os outros relatórios publicados sequer mencionam a figura do Tribunal Penal Internacional ${ }^{7}$.

Em 1997, Bill Clinton iniciou seu segundo mandato. Posen e Ross (1996, 1997) defendem que neste período o governo evoluiu de uma postura multilateral e cooperativa para uma que privilegiava a liderança dos Estados Unidos, mesclando estratégias do engajamento seletivo, da primazia e da segurança coletiva ${ }^{8}$. Os relatórios de 1997 a 2000, intitulados "National Security

6 Segundo Scheffer (200I), Bill Clinton demonstrou publicamente apoio à criação de uma corte penal internacional pelo menos em seis ocasiões: "William Jefferson Clinton, Remarks at the Opening of the Commemoration of "50 years After Nuremberg: Human Rights and the Rule of Law," University of Connecticut, 1995 Pub. Papers 1597, 1598; Statements of President William Jefferson Clinton, at the Army Conference Room in Pentagon, 33 Weekly Comp. Pres. Doc. 119 (Jan. 29, 1997); before the 52nd Session of the United Nations General Assembly, id. at 1389 (Sept. 22, 1997); in Honor of Human Rights Day, the Museum of Jewish Heritage, New York, id. at 2003 (Dec. 9, 1997); at a White House Press Briefing on Bosnia, id. at 2074 (Dec. 18, 1997); and William Jefferson Clinton, Remarks by the President to Genocide Survivors, Assistance Workers, and U.S. and Rwanda Government Officials, Kigali Airport, Kigali, Rwanda, 34 id. at 497 (Mar. 25, 1998").

7 Interessante mencionar que o ex-promotor do Tribunal ad hoc para a ex-lugoslávia. Richard Goldstone, acusou as potências ocidentais que controlavam a missão de paz na Bósnia (Estados Unidos, Reino Unido e França) de conspirar contra o aprisionamento dos indiciados, apesar da obrigação implícita nos acordos de Dayton de fazê-lo e concluiu que a situação representava um mau prenúncio para a negociação de uma corte penal internacional permanente (PATRIOTA, 2010, p. 157).

8 Posen e Ross $(1996,1997)$ apresentaram quatro tipos de concepções estratégicas que tradicionalmente são tidas como influências para os tomadores de decisão nos Estados Unidos - Neoisolacionismo, engajamento seletivo, segurança cooperativa e a primazia. O Neoisolacionismo corresponde à linha contemporânea de defensores da restrição da atuação política e militar norte-americana nos assuntos estrangeiros, especialmente no que se refere à postura de promotor da ordem internacional. O Engajamento Seletivo é embasado pelo argumento de que os Estados Unidos devem restringir sua atuação àquelas ocasiões que envolvam possíveis conflitos entre as grandes potências, questóes de fundamental importância para o interesse nacional, como, por exemplo, o acesso norte-americano a fontes de energia. A segurança cooperativa, por sua vez, está 
Strategy for a New Century", mantêm os objetivos enumerados nos documentos anteriores, reafirmam a preponderância dos Estados Unidos como polo de poder e liderança, bem como a importância do engajamento internacional para a promoçáo da paz e prosperidade.

Sobre o tema dos direitos humanos, os relatórios reafirmam o compromisso de assegurar os princípios internacionais desses direitos e proteger os grupos mais vulneráveis ou tradicionalmente oprimidos. Para esse fim, o documento prevê medidas de reforço da Comissáo de Direitos Humanos da Organização das Naçôes Unidas, mecanismos de proteçáo dirigidos às violaçóes do direito humanitário, como os tribunais ad hoc para a ex-Iugoslávia e Ruanda (THE WHITE HOUSE, 1998, p. 34).

O Tribunal Penal Internacional ficou fora do relatório de 1998, ano de sua criação. Também no relatório do ano 2000 o Tribunal Penal Internacional nâo foi mencionado a despeito de, no final do mandato, o governo Bill Clinton assinar o seu tratado constitutivo 9 . O compromisso norte-americano pela responsabilização das mais graves violaçóes dos direitos humanos privilegiou o enfoque ad hoc.

Vale ressaltar que o fato de os Estados Unidos serem o país com o maior contingente militar no exterior gerou uma preocupaçáa especialmente por parte do Pentágono com relaçáo à jurisdiçáo do Tribunal Penal Internacional para cidadáos norte-americanos envolvidos em intervençóes armadas e operaçóes de paz.

Outra mençáo no documento de 2000 que leva a refletir sobre a posição ambígua da administraçáo Bill Clinton com relaçáo ao Tribunal Penal Internacional é a da criaçáo de uma Comunidade de Democracias que poderia substituir o Conselho de Segurança na legitimação das intervenções armadas lideradas pelos Estados Unidos. O reconhecimento de que uma reforma da Organização das Naçóes Unidas náo seria feita em curto prazo e a convicçáo da necessidade do uso da força em situaçóes de ameaça à paz ou aos valores

relacionada à defesa da promoção de ações conjuntas e multilaterais para a garantia da ordem internacional. Por fim, a primazia parte da argumentação de que a segurança dos Estados Unidos e a paz mundial somente serão garantidas com a manutenção dos Estados Unidos como poder preponderante no cenário internacional.

9 Vale lembrar que o presidente Bill Clinton, ao assinar o tratado, declarou que, em razão das "graves falhas" percebidas no documento, não recomendava a ratificação deste. 
norte-americanos influenciaram os processos de intervençōes humanitárias que se caracterizaram por "um grau crescente de desconhecimento da autoridade do Conselho de Segurança" e pelo "relativo unilateralismo" visto na intervenção da Organização do Tratado Atlântico Norte (OTAN) em Kosovo (LEIS, 2009).

Assim, em um contexto de revisão da política internacional norte-americana sobre a legitimaçáo do uso da força e das organizaçóes internacionais que cumprem esse papel, a aprovaçáo de um sistema de justiça penal internacional que permite ao seu promotor iniciar investigaçóes sobre os chamados crimes de agressão e, portanto, julgar a legitimidade das intervençōes armadas gerou inúmeras controvérsias entre os membros da administraçáo e também nos debates no Congresso norte-americano.

Em contrapartida, é interessante perceber que os tribunais ad hoc, voltados para julgar militares e civis de regióes sem governo, ou para os líderes de estados considerados "fora da lei" aparecem em todos os relatórios de estratégia de segurança nacional como meio para alcançar os objetivos ligados à promoçăo dos valores norte-americanos de justiça, liberdade, democracia e direitos humanos.

\subsection{Os instrumentos de justiça internacional na grande estratégia de George W. Bush}

Em 2001, o republicano George W. Bush assumiu a presidência dos Estados Unidos com uma forte influência neoconservadora na sua administração. $\mathrm{O}$ presidente defendia uma postura agressiva com o aumento de gastos militares, mas restritiva com a proposta de um menor envolvimento em contendas internacionais.

Ikemberry (2009) defende que o governo George W. Bush passou por diferentes fases. A primeira, realista, foi marcada pelo crescente unilateralismo e pela crítica ao multilateralismo liberal dos anos Clinton. Segundo Skidmore (2005), essa característica da política externa pôde ser percebida nos primeiros anos da administração W. Bush com a rejeição do Protocolo de Kyoto e a anulaçáo da assinatura do Estatuto do Tribunal Penal Internacional.

A segunda fase se inicia com a sistematização da estratégia após os episódios de 11 de setembro de 2001. A publicação do "National Security Strategy" 
em setembro do ano seguinte trouxe a público a visão dos Estados Unidos como o único provedor de um bem público global - segurança na nova ordem mundial. Como consequência da posiçáo assumida pelos Estados Unidos, ficava subentendido que, em retribuição, o mundo deveria onerar menos os Estados Unidos com regras e instituiçóes da antiga ordem (IKEMBERRY, 2009, p. 7).

Nesse contexto, a estratégia da "preemption" ou da prevenção foi apresentada no relatório de 2002. De acordo com essa estratégia, ameaças como a do terrorismo devem ser enfrentadas de forma antecipada ${ }^{10}$. A açáo ligada ao conceito de "preemption" é caracterizada pela antecipação da ação pelo Estado que está sob ameaça iminente, podendo considerá-la como legítima defesa, já a ação preventiva é ofensiva, normalmente escolhida quando o Estado quer manter o equilíbrio de poder em seu favor. Ambos os conceitos aparecem no relatório, segundo Storti, de forma proposital (STORTI, 2009, p. 168). Brzezinski (2004) aponta que a confusão conceitual liberou os Estados Unidos para as operaçóes militares contra os inimigos, sem que essas açóes passassem pelo crivo da comunidade internacional e da opiniáo pública doméstica.

Segundo Jervis (2003), a doutrina Bush tem quatro elementos: (1) a crença na importância do regime doméstico estatal na determinação das políticas externas e a percepçáo relacionada de que os Estados Unidos vivem um momento de oportunidade para transformar a política internacional; (2) a percepçáo que grandes ameaças devem ser combatidas com políticas novas e vigorosas, notadamente a guerra preventiva; (3) a escolha da açáo unilateral, quando necessário; e (4) a sensaçáo clara de que a paz e a estabilidade exigem dos Estados Unidos a afirmaçáo da sua supremacia na política mundial.

A importância da crença da expansáo dos valores democráticos como força transformadora do cenário internacional também é ressaltada. A realização dos direitos humanos, de acordo com o relatório de 2002, está atrelada ao objetivo da propagação da democracia no globo. De outro lado, a mesma estratégia que objetivou a promoçáo da liberdade global, conferiu prioridade ao combate do terrorismo e justificou políticas domésticas que cercearam as liberdades civis.

10 O terrorismo no relatório de 2002 foi associado às armas de destruição em massa e ao eixo do mal (Irãa, Iraque, Líbia, Coreia do Norte, Síria, Sudão e Cuba, classificados como rogue states pelo governo Bill Clinton). Confira Relatório Patterns of Global Terrorism, datado de 200 I e publicado em 2002. 
É interessante também observar que o relatório de 2002 traz várias mençôes sobre a importância da busca pela justiça na estratégia de engajamento internacional dos Estados Unidos. O discurso do presidente George W. Bush, em maio de 2003 na Alemanha, citado no documento, afirma: "We build a world of justice, or we will live in a world of coercion. The magnitude of our shared responsibilities makes our disagreements look so small." (THE WHITE HOUSE, 2002, p. 9).

Os esforços empreendidos pelo governo George W. Bush para julgar Saddam Hussein e o discurso favorável à criaçáo de tribunais semelhantes aos tribunais da ex-Iugoslávia, Ruanda e Serra Leoa são exemplos dessa política. De outro lado, o Tribunal Penal Internacional sofreu forte oposiçáo do governo George W. Bush, que declarou, em várias ocasióes, que o sistema de justiça penal internacional estabelecido em Roma ameaça os interesses norte-americanos (THE WHITE HOUSE, 2002, p. 31).

O "American Service Members Protection Act" determinou o corte de assistência econômica e militar em dois programas do governo para os Estados que ratificassem o Estatuto do Tribunal Penal Internacional. A legislaçáo, anteriormente mencionada, é uma das muitas medidas de combate ao Tribunal Penal Internacional ${ }^{11}$.

A hostilidade da administraçáo de W. Bush com relação ao Tribunal Penal Internacional foi manifestada de outras duas formas: a aprovação de

11 Os cortes de ajuda orçamentária para paises que ratificaram o Tratado de Roma começaram a ser elaborados pelo legislativo norte-americano ainda durante o governo Bill Clinton. O American Service Members' Protection Act $(A S P A)$ sobre a política norte-americana de ajuda militar e econômica em matéria de segurança e defesa previu cortes de ajuda militar (Internarional Military Education and Traininf - IMET e Foreign Military Funds - FMF) para Estados membros do Tribunal exceto os Estados membros da Organização do Tratado Atlântico Norte (OTAN), grandes aliados não membros da OTAN (nomeadamente Austrália, Egito, Japão, Argentina, República da Coreia, Nova Zelândia e Taiwan) e os Estados que assinaram os Acordos Bilaterais de Não Entrega. A lei também menciona a restrição à participação dos Estados Unidos nas missões de operações de paz nos casos que as tropas estejam em risco de serem indiciadas pelo Tribunal. A restrição somente pode ser dispensada nos casos que o Presidente declarar que a participação norte-americana é do interesse nacional. $A$ lei também proibiu a cooperação entre os Estados Unidos e o Tribunal e permitiu ao Presidente usar qualquer meio necessário para liberar cidadãos norte-americanos e de países aliados da custódia do Tribunal. Outra iniciativa legislativa de oposição ao Tribunal foi a Emenda Nethercutt, promulgada em 8 de dezembro de 2004 pelo presidente W. Bush, que suspendeu a ajuda do Economic Support Fund aos membros do Tribunal Penal Internacional. Os cortes foram adotados nos anos fiscais de 2005, 2006 e 2008. Nos anos de 2005 e 2006 foi registrado um corte de 127,65 milhões de dólares de ajuda externa através do ASPA e Emenda Nethercutt (MAIA, 2012, p. 177). 
resoluçōes do Conselho de Segurança restringindo a atuação do Tribunal Penal Internacional e a iniciativa dos Acordos Bilaterais de Imunidade (BIAS).

A iniciativa de bloqueio do indiciamento de cidadáos norte-americanos por meio de resoluçóes do Conselho de Segurança teve início com as negociações sobre a renovação das operaçôes de paz no Timor Leste e na Bósnia e Herzegovina em maio de 2002. Os Estados Unidos ameaçaram não mais aprovar missóes de paz enquanto seus oficiais náo estivessem imunes à jurisdiçáo do Tribunal Penal Internacional.

Muitas críticas foram dirigidas ao posicionamento norte-americano nas reunióes subsequentes do Conselho de Segurança. A resoluçáo 1422, de 12 de julho de 2002, foi aprovada por unanimidade, conforme o artigo 16 do Tratado que permite suspender julgamentos por períodos renováveis, o que bloqueou antecipadamente o indiciamento de cidadáos provenientes de Estados que náo tivessem ratificado o Tribunal Penal Internacional. Negroponte declarou que a resoluçáo foi o primeiro passo da presidência dos Estados Unidos na determinaçáo de proteger os cidadãos e soldados dos Estados Unidos do Tribunal Penal Internacional (NEGROPONTE, 2002, p. 1).

A referida resoluçáo foi renovada em 2003, mas, em 2004, em meio às críticas sobre a tortura de prisioneiros de guerra em Abu Graib cometida por militares norte-americanos e a sinalizaçáo da maioria das delegaçóes de abstençáo ou voto contrário, os Estados Unidos não solicitaram nova renovação. Todavia, o Embaixador Cunningham declarou que, na ausência de nova resoluçáo, os Estados Unidos levariam em conta o "risco Tribunal Penal Internacional" na avaliação de quando contribuir para as operaçóes de paz e ressaltou também as iniciativas bem sucedidas das negociaçóes de acordos bilaterais de imunidade.

Os Acordos Bilaterais de Imunidade (BIAS) podem ser considerados como uma estratégia de boicote ao funcionamento do Tribunal Penal Internacional. Esses acordos foram elaborados conforme o dispositivo previsto no artigo 98, que na Conferência de Roma foi defendido pela delegaçáo norte-americana. $\mathrm{O}$ artigo trata da cooperação internacional e assistência judicial para evitar conflitos com obrigaçóes internacionais decorrentes de outros acordos firmados. Os Estados Unidos justificaram a possibilidade de realizar acordos bilaterais de não entrega de cidadáos norte-americanos para o Tribunal Penal Internacional por meio desse dispositivo. O Tribunal Penal 
Internacional não corroborou com essa interpretaçáo, mas até o final do governo W. Bush foram realizados acordos com mais de cem Estados ${ }^{12}$.

O segundo relatório de estratégia de segurança nacional foi publicado em 2006 com algumas mudanças de conteúdo, entre elas a promoçáo da liberdade e da democracia como medida mais efetiva de promover e fortalecer a estabilidade internacional com a redução de conflitos regionais e a contenção do terrorismo. Outra mudança importante foi a de relacionar a estratégia com o conceito de "preemption" e enfatizar a temática do multilateralismo, inclusive com a menção explícita da necessidade de reforma da Organização das Nações Unidas para que ela possa enfrentar os novos desafios do cenário internacional, inclusive os que envolvem a aprovação do uso da força.

O Tribunal Penal Internacional não aparece no relatório de 2006, diferentemente do relatório anterior, o qual enfatizou a necessidade de combate ao instrumento que, na concepção da administração W. Bush, ameaça os interesses norte-americanos. $\mathrm{O}$ fato de o relatório de 2006 náo mencionar o Tribunal Penal Internacional pode ser compreendido como resultado da mudança de retórica do governo sobre temas multilaterais, bem como em razão dos altos custos das açóes de oposiçáo ao Tribunal, o que foi alertado pelos próprios membros da administração.

Em março de 2006, foi realizada uma audiência no Comitê de Relaçóes Exteriores no Senado sobre o impacto do American Service Members' Protection Act e alguns senadores, como Norm Coleman (republicano de Minnesota), apesar de abertamente favoráveis à lei, declararam preocupaçáo com os impactos desta nos esforços norte-americanos de promoçáo da segurança regional e internacional (U.S. SENATE, 2006, p. 7). O próprio Departamento de

12 Os acordos disponibilizados na página da Casa Branca são: Afeganistão, Albânia, Antígua e Barbuda. Argélia, Angola, Armênia, Azerbaijão, Bahrein, Bangladesh, Belize, Benin, Bolivia, Bósnia e Herzegovina, Botsuana, Burkina Faso, Burundi, Butão, Brunei, Camarões, Camboja, Cabo Verde, Cazaquistão, Chade, Cingapura, Colômbia, Congo-Brazzaville, Cômoros, Costa do Marfim, Djibuti, Dominica, Egito, El Salvador, Emirados Árabes Unidos, Eritréia, Etiópia, Fiji, Filipinas, Gabão, Gâmbia, Geórgia, Gana, Guiana, Guiné Bissau, Guiné Equatorial, Granada, Haiti, Honduras, Ilhas Marshall, Ithas Maurício, Ilhas Salomão, Índia, Israel, Jordânia, Kiribati, Kuwait, Laos, Libéria, Macedônia, Madagascar, Mongólia, Nauru, Nepal, Nicarágua, Nigéria, Omã, Paquistão, Palau, Panamá, Papua Nova Guiné, Quirguistão, República Centro Africana, República Democrática do Congo, República Dominicana, Romênia, Ruanda, São Tomé e Príncipe, Senegal, Serra Leoa, Seychelles, Sri Lanka, São Cristóvão e Neves, Tadjiquistão, Tailândia, Timor Leste, Togo, Tonga, Tunisia, Turcomenistão, Tuvalu, Uganda, Uzbequistão, lêmen, Zâmbia. 
Estado, já no ano anterior, havia externado preocupação com a redução das oportunidades de treinamento de equipes militares, no exterior.

Sobre a mudança de posição do governo W. Bush em 2006, é importante também citar a resoluçáo 1593 do Conselho de Segurança, que permitiu o encaminhamento da situaçáo de Darfur no Sudáo ${ }^{13}$ ao Tribunal Penal Internacional aprovada com a abstenção dos Estados Unidos.

Considerada uma das mais graves crises humanitárias dos últimos tempos, os conflitos iniciados no ano de 2003, em Darfur, Sudáo, tiveram como consequência milhares de mortes, deslocados internos e refugiados. Os crimes contra a humanidade e os crimes de genocídio chocaram a comunidade internacional. Nesse contexto e coerentes com sua estratégia, o governo W. Bush inicialmente defendeu no Conselho de Segurança que o julgamento dos criminosos acontecesse em um tribunal africano e ameaçou vetar o encaminhamento do caso para o Tribunal Penal Internacional.

A nova posiçáo do governo George W. Bush com relaçáo ao Tribunal Penal Internacional foi vista como incoerente por parte da comunidade política norte-americana que defende que os princípios do Tribunal Penal Internacional são contrários aos valores do autogoverno democrático. Sobre o tema, David Rivkin e Lee Casey publicaram vários artigos sugerindo que os perpetradores do genocídio em Darfur poderiam ser julgados por um tribunal africano, como o Tribunal ad hoc para Ruanda. Os debates internos no governo acabaram tendo como resultado a aquiescência do governo George W. Bush do encaminhamento pelo Conselho de Segurança das situações de violaçáo de direitos humanos em Darfur para o Tribunal Penal Internacional.

\subsection{Os instrumentos de justiça internacional na grande estratégia de Barack Obama}

O democrata Barack Obama elegeu-se em 2008 como o presidente mais votado da história dos Estados Unidos, com o slogan "Yes, we can". Sua vitória ocorre em meio às expectativas com relaçáo a uma mudança drástica na condução da estratégia de engajamento internacional norte-americana. Essas

13 Confira nota de rodapé $n$. 3 sobre o julgamento dos crimes contra a humanidade e de genocídio sob jurisdição do Tribunal Penal Internacional. 
expectativas, de certa forma se traduziram na premiaçáo do Nobel da Paz em 2009, ainda no primeiro ano de seu mandato como presidente dos Estados Unidos.

A nova doutrina para a grande estratégia do governo Obama, entretanto, náo foi publicada no primeiro ano do governo. Foi somente em 2010 que o documento foi apresentado, já cercado de muitas críticas. Alguns estudiosos, como Mersheimer e Niall Ferguson, declararam à época que a administraçáo Obama náo tinha uma estratégia clara ${ }^{14}$. Outros estudiosos da grande estratégia, como Ikemberry, defenderam que o governo Obama tem uma estratégia resultado da herança dos problemas da administraçáo anterior, mas que também responde ao novo contexto internacional ${ }^{15}$.

Segundo Soller (2010), a doutrina Obama aponta para uma mudança conceitual na grande estratégia, em que a potência dominante dá lugar a uma potência em posição de liderança, mas em processo de retraimento. A estratégia também apresenta quatro afirmaçóes importantes que denotam uma mudança profunda de percepçáo sobre o sistema internacional. Primeiro afirma a existência de novas potências (entre elas, Rússia, China e Índia). Segundo, afirma que o sistema internacional está em transição. Em terceiro lugar, assume que os Estados Unidos náo podem resolver sozinhos os desafios da atualidade. Em quarto, anuncia que a característica fundamental da grande estratégia é a de buscar estabelecer abordagens cooperativas entre os Estados que possam produzir resultados. Como pano de fundo, é possível observar os valores tradicionais da política externa dos Estados Unidos - liberdade dos mares, democracia e justiça.

Nesse contexto, o Relatório de Segurança Nacional apresenta três desafios: (1) encontrar uma nova orientaçáo para a liderança americana abalada com a doutrina da guerra contra o terror; (2) responder à fase de transição de poder no sistema internacional e ajustar o papel dos Estados Unidos;

14 O colunista Jackson Diehl, por exemplo, escreveu no Washington Post, que a administração Obama é notável pela falta de estratégia e de estrategistas. Disponivel em: < http://www.foreignaffairs.com/articles/679/9/ daniel-w-drezner/does-obama-have-a-grand-strategy>. Acesso em: 21 maio 2012.

15 Pecequilo (2010) afirma que o relatório de segurança nacional da administração Obama, "cercado de promessas", chocou-se com a realidade de uma nação fragmentada por disputas domésticas, por crises e pela lenta recuperação econômica. Ademais, o documento foi confrontado com práticas internacionais opostas à retórica apresentada. 
(3) garantir a segurança norte-americana face aos desafios transnacionais terrorismo, proliferaçáo de armas de destruição em massa e os chamados "rogue" e "failed states" - através de novos mecanismos multilaterais (SOLLER, 2010, p. 2).

O tema dos direitos humanos é citado inúmeras vezes no documento e aparece com forte ligação aos valores norte-americanos e à estratégia da promoçáo das democracias. De acordo com o documento, os "Estados Unidos apoiam a expansáo da democracia e dos direitos humanos no exterior porque governos que respeitam esses valores são mais justos, pacíficos e legítimos". Ademais, os Estados Unidos "também fazem isso porque o sucesso dessa açáo promove um ambiente de apoio aos interesses norte-americanos" (THE WHITE HOUSE, 2010, p. 37).

O documento também afirma que a história do país mostra que é mais fácil forjar consenso para as mudanças necessárias quando o trabalho com os outros Estados refletem o respeito ao direito do povo, e náo apenas os interesses daqueles que estáo no poder (THE WHITE HOUSE, 2010, p. 37). $\mathrm{O}$ tema da justiça internacional também está presente no relatório ligado ao tópico da ordem internacional que identifica mudanças consideradas "chaves", entre elas a cooperaçáo internacional para levar a julgamento aqueles que cometeram violaçóes ao direito internacional.

Contraditoriamente, em abril de 2011 a administração Obama declarou o sucesso da perseguição e morte de Osama Bin Laden, líder do grupo terrorista islâmico Al-Qaeda e um dos organizadores dos ataques de 11 de setembro. Bin Laden foi morto durante uma operaçáo da Agência Central de Inteligência CIA em uma região montanhosa do Paquistáo. Na ocasiāo, o presidente Barack Obama declarou para a imprensa que "a justiça” tinha sido feita.

No que se refere aos tribunais internacionais, o relatório de 2010 afirma que de Nuremberg à Iugoslávia e Libéria, os Estados Unidos têm observado que o fim da impunidade e a promoção da justiça náo são apenas imperativos morais, eles são forças estabilizadoras nas relaçóes internacionais (THE WHITE HOUSE, 2012, p. 48). Ademais, reforça que a administração apoiará o fortalecimento dos sistemas de justiça nacionais e manterá o apoio aos tribunais ad hoc e mistos. Sobre o Tribunal Penal Internacional, justifica que os Estados Unidos náo são parte do Estatuto de Roma e que a administraçáo 
continuará a proteger os oficiais norte-americanos. Afirma também que apoiará o encaminhamento de casos (que não envolvam cidadãos norte-americanos) ao Tribunal que estejam de acordo com os interesses e valores dos Estados Unidos.

Membros da administraçáo Barack Obama, como o Secretário de Defesa Robert Gates ${ }^{16}$ (Diretor da Agência Central de Inteligência - CIA no período George W. Bush), manifestou abertamente o seu entendimento de que o Tribunal Penal Internacional constitui uma ameaça à soberania nacional (ROVINE, 2001, p. 967).

A abordagem de Obama para o Tribunal Penal Internacional frustrou algumas organizaçóes de direitos humanos que acreditavam em uma mudança de postura do governo no apoio à adesáo ao instrumento. No governo Obama, os cortes de ajuda econômica e militar foram suspensos, mas é importante lembrar que já no final do governo George W. Bush essa era a orientaçáo. Durante a administraçáo Obama, náo foram buscados novos acordos bilaterais de imunidade, mas também não houve menção à extinçáo destes. Apesar de o compromisso da Administraçáo Obama permitir que o Tribunal Penal Internacional receba casos por meio do Conselho de Segurança ${ }^{17}$, náo há indícios de que haja a intenção de voltar a participar do Estatuto de Roma.

A participaçáo de delegaçáo norte-americana na Conferência de Revisão do Estatuto de Roma em Kampala, Uganda em maio e junho de 2010, marcou um período que Koh, assessor jurídico do governo norte-americano, chamou de transiçáo de uma relaçáo de hostilidade para relaçáo baseada no engajamento positivo com o Tribunal Penal Internacional.

No entanto, deixou claro em sua fala que o engajamento visa garantir que os interesses dos Estados Unidos sejam contemplados pelo Tribunal. De fato, em um dos principais temas da Conferência de Revisão, que foi o da definiçáo e das condiçóes para o exercício da jurisdiçáo sobre o crime de agressáo, os Estados Unidos foram contemplados no seu interesse de que Estados não

16 Robert Gates foi nomeado Secretário de Defesa em 18 de dezembro de 2006 e permaneceu no cargo até II de julho de 2011 .

17 O Estatuto do Tribunal Penal Internacional prevê que o Conselho de Segurança pode encaminhar casos de Estados não membros para julgamento. Recentemente, o caso da Libia foi recebido pelo Tribunal Penal Internacional com o apoio da administração Obama. 
membros do Tribunal não possam ser julgados pelo crime de agressão e que estados partes possam ter a oportunidade de suspenderem a jurisdição, se assim desejarem.

\section{Conclusão}

A comparaçáo dos documentos e informaçóes sobre a grande estratégia das quatro administraçóes para os direitos humanos mostra que o tema aparece em uma agenda bilateral e assistencialista. $\mathrm{O}$ tema ganha relevância na agenda multilateral quando aparece subjacente aos temas ligados à segurança e expansão das democracias. O tema da justiça internacional, por sua vez, aparece ligado aos valores norte-americanos. É interessante observar que as quatro administraçóes estudadas defendem o estabelecimento de tribunais ad hoc e mistos para o julgamento dos crimes contra o direito internacional, especialmente os cometidos por indivíduos provenientes dos chamados rogue states e failed states. Mesmo nos governos republicanos de George H. W. Bush e George W. Bush é possível observar iniciativas de criação e apoio a esses tribunais.

No que se refere ao Tribunal Penal Internacional, tanto a administraçáo democrata (representada pelos governos de Bill Clinton e de Barack Obama) como a republicana (representada pela administraçáo George W. Bush) se manifestaram contrárias à ideia do estabelecimento de um sistema de justiça penal internacional permanente com característica de supranacionalidade ${ }^{18}$.

As variaçóes da política das três administraçóes - Bill Clinton, George W. Bush e Barack Obama - encontram-se nas diferentes interpretaçóes das suas equipes sobre o alcance da jurisdição do Estatuto de Roma e na tática usada para limitar a atuaçáo do Tribunal.

Clinton, ao assinar o Estatuto de Roma, náo o recomendou para a ratificaçáo, tendo em vista o que ele considerou como "falhas graves" no documento, ou seja, os dispositivos que conferem independência ao Tribunal e que permitem que a sua jurisdiçâo alcance cidadáos de Estados náo membros do Estatuto de Roma. A tática era a de, com a assinatura do Estatuto, garantir a possibilidade de buscar revisóes no documento que interessassem aos Estados

18 Não é possivel tecer considerações sobre a posição da administração George H. W. Bush sobre a criação de um tribunal penal internacional permanente, tendo em vista que o tema ingressou na agenda de política internacional no governo William Clinton. 
Unidos, bem como a de usar o instrumento de justiça, quando conviesse aos interesses norte-americanos.

A retórica de Barack Obama parece seguir a mesma orientação tática. $\mathrm{O}$ presidente defendeu o encaminhamento de casos de interesse norte-americano para o julgamento no Tribunal Penal Internacional, mesmo náo sendo parte do Estatuto de Roma, enviou uma grande delegação para acompanhar as negociaçóes da Conferência de Revisáo em Kampala, mas náo cogita uma adesáo norte-americana ao referido Tribunal.

É interessante perceber que as justificativas para a não aceitação do Estatuto do Tribunal Penal Internacional são as mesmas para as três administraçóes. No entanto, na administração W. Bush, considerando o enorme contingente militar norte-americano em operaçóes de paz e intervençóes armadas e que o Tribunal Penal Internacional tem jurisdiçáo sobre indivíduos de Estados náo membros, o instrumento de justiça internacional passou a ser visto como uma ameaça.

Além disso, a estratégia de W. Bush era a de evitar um compromisso internacional que poderia entrar em conflito com as instituiçóes norte-americanas e garantir a autonomia dos Estados Unidos na consolidaçáo da supremacia estadunidense e do uso, quando necessário, unilateral da força na concretizaçáo dos objetivos norte-americanos, coerentes com a chamada Doutrina Bush.

É evidente que a inflexão tática do governo George W. Bush não foi apenas retórica e pode ser caracterizada por um conjunto de açóes com a finalidade de boicotar o funcionamento do Tribunal. No entanto, muitas das açóes de oposiçáo ao Tribunal Penal Internacional empreendidas durante a administração George W. Bush e polemizadas por antigos integrantes do governo Bill Clinton, como, por exemplo, as críticas de Scheffer (2005) aos acordos bilaterais de imunidade, não estavam fora do horizonte das alternativas consideradas por integrantes da própria administração Clinton.

É interessante observar também que o abrandamento da oposição da administração George W. Bush no seu segundo mandato, identificada na permissáo do encaminhamento da situaçáo de Darfur para o Tribunal Penal Internacional, náo se converteu em aceitaçáo ou apoio para o referido Tribunal. A tática da administração nesse período pode ser percebida como mais próxima daquela defendida pela administração Clinton e da adotada na administração Obama, pelo menos no que se refere ao uso do sistema 
permanente de justiça internacional quando conveniente e como uma forma de buscar aproximaçáo com os Estados aliados em um contexto marcado pela expansão do antiamericanismo e da ampliaçáo das críticas dirigidas à política unilateral do período George W. Bush.

Nesse sentido, a explicação de que a posição dos Estados Unidos para o Tribunal Penal Internacional reflete a posição de hegemonia que ocupa e a necessidade de estar desonerado de compromissos internacionais para poder atuar de forma mais livre no sistema internacional pode ser acolhida, mas é limitada.

A posição das diferentes administraçôes preocupadas em não permitir a jurisdiçáo do Tribunal para nacionais norte-americanos tem também forte influência de grupos políticos que defendem a superioridade das instituiçóes norte-americanas e de sua Constituiçáo. Vale também ressaltar o que Ignatieff (2005) chama de excepcionalismo jurídico norte-americano. Os Estados Unidos não aceitam que seus nacionais possam ser julgados por tribunais alienígenas, instrumentos que muitas vezes não possuem, nessa visão, as garantias necessárias para o devido processo.

\section{Referências}

APODACA, C. Understanding U.S. human rights policy: a paradoxical legacy. New York: Routledge, 2006.

ART, R. J. A defensible defense: America’s grand strategy after the cold war. International Security, v. 15, n. 4, p. 5-53, 1991. Disponível em: <http://www.jstor.org/stable/2539010>. Acesso em: 12 mar. 2009.

BASSIOUNI, M. C. Posto-conflict justice in Iraq: an appraisal of the Iraq special tribunal. Cornell International Law Journal, Ithaca, New York, n. 319, p. 103-166, 2005.

BOLTON, J. R. American justice and the international criminal court: remarks at the American Enterprise Institute. Washington DC, Nov. 2003.

BRZEZINSKI, Z. To lead, United States must give up paranoic policies. New Perspectives Quarterly, Los Angeles, v. 21, p. 23-26, 2004.

DORFF, R. H. A primer in strategy development. In: CERAMI, J. R.; HOLCOM Jr., J. F. (Ed.). U.S. Army War College Guide to Strategy. Carlisle, Pennsylvania: U.S. Army War College, 2001. 
DUMBRELL, J.; BARRET, D. M. The making of U.S. foreigh policy. Manchester: University Press, 1997.

FORSYTHE, D. P. Human rights in international relations. Cambridge: Cambridge University Press, 2000.

FUKUYAMA, F. The end of history? The National Interest, summer 1989. Disponível em: <http://www.wesjones.com/eoh.htm>. Acesso em: 30 jun. 2011.

HERRING, G. C. From colony to superpower: U.S. foreign relations since 1776. Oxford: Oxford University Press, 2008.

HUNTINGTON, S. P. The clash of civilizations? Foreign Affairs, Tampa, Flórida, v. 72, n. 3, summer 1993.

IGNATIEFF, M. (Ed.). American exceptionalism and human rights. Princeton: Princeton University Press, 2005.

IKEMBERRY, G. J. Woodrow Wilson, the Bush agenda, and the future of internationalism. In: IKEMBERRY, G. J. et al. The crisis of American foreign policy: wilsonianism in the twenty-first century. Princeton: Princeton University Press, 2009.

JERVIS, R. Understanding the Bush doctrine. Political Science Quaterly, v. 118, n. 3, p. 365-388, 2003.

LAYNE, C. Rethinking american grand strategy hegemony or balance of power in the twenty-first century? World Policy Journal, New York, v. 15, p. 8-28, 1998.

LEIS, H. R. Dilemas da política internacional e o unilateralismo da política externa dos Estados Unidos no século XXI. In: DINIZ, E. (Org.). Estados Unidos: política externa e atuação na política internacional contemporânea. Belo Horizonte: Ed. PUC Minas, 2009.

MAIA, M. O tribunal penal internacional na grande estratégia norte-americana (1990-2008). Brasília, DF: FUNAG, 2012.

MEARSHEIMER, J. J. The false promise of international institutions. International Security, Cambridge, Massachusetts, v. 19, n. 3, p. 5-49, 1998.

MERTUS, J. A. Bait and switch: human rights and U.S. foreign policy. New York: Routledge, 2004.

NEGROPONTE, J. D. Discurso dirigido ao Conselho de Segurança da Organizaçáo das Naçóes Unidas sobre a situaçáo da Bósnia e Herzegovínia, 12 de julho de 2002. AMICC. Disponível em: < http://www.amicc.org/docs/Negroponte_1422.pdf>. Acesso em: 12 abr. 2011. 
NYE JR., J. S. What new world order. Foreign Affairs, Tampa, Flórida, v. 71, n. 2, p. 83-96, 1992. PATRIOTA, A. A. O conselho de segurança após a guerra do Golfo: a articulação de um novo paradigma de segurança coletiva. Brasília, DF: Instituto Rio Branco; FUNAG; Centro de Estudos Estratégicos, 2010.

PECEQUILO, C. S. A Política Externa dos Estados Unidos: continuidade ou mudança?, Porto Alegre: Editora da UFRGS, 2005.

PECEQUILO, C. S. As grandes estratégias dos Estados Unidos (1989-2010). Boletim Meridiano 47, vol.11, n. 120, 2010, pp. 11-17.

POSEN, B. R. e ROSS, A. L.. Competing visions for U.S. Grand Strategy. International Security, v. 21, n. 3, winter, 1996-1997.

RALPH, J. Between cosmopolitan and american democracy: understanding U.S. opposition to the International Criminal Court. International Relations, London, v. 15, p. 195-212, 2003.

ROVINE, A. W. Memorandum to Congress on the ICC from ICC from current and past presidents of the ASIL. American Journal of International Law, Washington DC, n. 95, 2001.

SCHABAS, W. A. United States hostility to the International Criminal Court: it's all about the Security Council. EJIL, Florence, v. 15, n. 4, p. 701-720, 2004.

SCHARF, M. P.. Balkan Justice: The Story Behind the First International War Crimes Trial Since Nuremberg. Durham: Carolina Academic Press. 1997.

SCHEFFER, D. J. Staying the Course with the International Criminal Court. Cornell International Law Journal, v. 35, n. 47, 68 - 87, 2001.

SIKKINK, K. U.S. human rights policy and Latin America. Ithaca, Londres: Cornell University Press, 2004.

SKIDMORE, D. Understanding the unilateralist turn in U.S. foreign policy. Foreign Policy Analysis, Missouri, n. 2, p. 201-228, 2005.

SNIDER, D. M.; NAGL, J. A. The national security strategy. In: CERAMI, J. R.; HOLCOM JR., J. F. (Ed.). U.S. Army War College guide to strategy. Carlisle, Pennsylvania: U.S. Army War College, 2001.

SOLLER, D. O relatório Albright e a grande estratégia Obama: um caso de convergência? Relaçóes Internacionais, set. 2010.

STEINMETZ, S. Democratic transition and human rights: perspectives on U.S. foreign policy. New York: State University of New York Press, 1994. 
STORTI, J. Enfrentando as novas ameaças: estratégia e política internacional norte-americanas no pós guerra fria. Campinas, SP: Unicamp; Instituto de Filosofia e Ciências Humanas, 2009.

THE WHITE HOUSE. A National Security Strategy of Engagement and Enlargement. Washington: The White House, fevereiro de 1994.

A national security strategy of engagement and enlargement. Washington DC: The White House, Feb. 1995. . Washington DC: The White House, Feb. 1996. Washington DC: The White House, May 1997.

A national security strategy for a new century. Washington DC: The White House, Oct. 1998. . Washington DC: The White House, Dec. 1999. . Washington DC: The White House, Dec. 2000.

National security strategy. Washington DC: The White House, Mar. 1990.

. Washington DC: The White House, Aug. 1991.

. Washington DC: The White House, May 2010.

The national security strategy of United States of America. Washington DC: The White House, Sept. 2002. Washington DC: The White House, Mar. 2006.

Remarks by President Bush and President Alvaro Uribe of Colombia, 26 set. 2002b. Disponível em: <http:/www.scoop.co.nz/stories/WO0209/S00264/bush-colombia-presidenturibe-discuss-terrorism.htm>. Acesso em: 12 abr. 2011.

National Security Strategy. Washington: The White House, maio de 2012.

U.S. DEPARTMENT OF DEFENSE. Joint publication 1-02: Department of Defense dictionary of military and associated terms. Washington DC: [U.S. Department of Defense], 12 abr. 2001. Com emendas de 30 set. 2008. Disponível em: <www.dtic.mil/doctrine/jel/new_pubs/jp1_02. pdf $>$. Acesso em: 20 set. 2008.

U. S. SENATE (Committee on Foreign Relations) The Impact on Latin America of the American Servicemembers' Protection Act: Hearing before the Subcommitee on Western Hemisfere, Peace Corps and Narcotic Affairs. Washington: U.S. Government Printing Office, 8 de março de 2006. 


\section{The grand strategy of the United States to the International Penal Court in post-Cold War}

\section{Abstract}

The present research has as its objective an examination of the policies of the United States with regard to the International Penal Court from the perspective of the American foreign policy strategy. For the analysis, the review begins with the end of the "cold war" period. As a time of interest in the creation of international courts, the presidencies of George H. W. Bush (19891992), Bill Clinton 1993-2000), George W. Bush (200I-2008) and Barack Obama (2009-20I2) are considered. The theme of international justice is inserted into the international political debate, as well as the American foreign policy debate, with implications for the U.S. grand strategy. The conclusion of the analysis presents considerations as to the underlying consensus of the positions of the United States regarding the International Criminal Court. In general, the positions of the international regimes as to human rights and specific dimensions of opposition in the discourse of the governments involved are observed. These dimensions represent North American values and the distinct interpretations of the level of commitment of the US Government as a permanent institution of international justice.

Keywords: foreign policy - United States, international criminal courts, world politics, human rights 